\title{
Exploring to Service Innovations in Shanghai Metro System: Based on the Model of MFCSI
}

\author{
Jutamart Limsupanark ${ }^{1}, \mathrm{Xu}$ Ming $^{1}$, Wang $\mathrm{Yu}^{1} \&$ Dai Wenwen ${ }^{1}$ \\ ${ }^{1}$ Glorious Sun School of Business and Management, Donghua University, Shanghai, China \\ Correspondence: Jutamart Limsupanark, Glorious Sun School of Business and Management, Donghua University \\ No. 1882 Yan'an West Road, Changning District, Shanghai 200051, China. Tel: 86-150-2128-5354 or \\ 66-868-883-960. E-mail: ju_meichai@yahoo.com
}

Received: September 16, 2014

Accepted: December 11, 2014 Online Published: December 25, 2014

doi:10.5539/ibr.v8n1p106

URL: http://dx.doi.org/10.5539/ibr.v8n1p106

\begin{abstract}
This paper studies service innovations that have been developed in Shanghai Metro System within last seven years. The information about service innovations are mainly gathered from Shanghai Metro's official website concentrating on the model of five levels of classification of service innovation in enterprises (MFCSI)which was developed by a group of scholars in Donghua University, China. The survey on passengers and interviews on the operation and managerial staffs are also carried out related with their services and innovations. Data collection was done via Websites-investigation, field observation and interview in five metro stations in Shanghai. Totally 18 service innovation cases are analyzed by the Model of MFCSI. Meanwhile, some solutions for improving were found for better development of MFCSI as a new measuring tool concerning the increasing service firms' competence, which is similar to the new points in the service science field with the potential to be used more further in services firms.
\end{abstract}

Keywords: service innovation, MFCSI Model, metro service, Shanghai metro, subway, customer satisfaction

\section{Introduction}

The Model of Five Level Classifications of Service Innovation in enterprises (MFCSI) is a recent beneficial measurement employed to detect the innovative situation inside the company, which is developed by a group of scholars in Donghua University Shanghai China.

The Shanghai metro system is one of the fastest-growing rapid systems in the world (Wikipedia, 2013). It consists of subway and sky-train systems. The first line was opened in April, 1995. Eighteen years later in 2013, Shanghai metro system operated 12 metro lines and 287 stations with 439 KM. (Shanghai Statistics Bureau, 2013a) route length. By 2020, Shanghai will operate 22 lines of metro with 877 KM expanded route length. It will be one of the largest metro systems in the world. Nowadays the amount of passengers in Shanghai Metro System reaches 6.7 million each day and 8.48 million (Wu Qiang, 2013) during prime time, before and after office hour (Anonymous, 2012b). The passengers approximately thirty percents of Shanghai's population. The effective, stable and disciplined management to provide the best solution for a large group of people is the big challenge for the city's transit system, of which the transfer guiding system is considered to be an important part. The purposes of this paper are to find the distribution channel of various classes of service innovation inside the enterprises, which is based on the MFCSI, to examine the driven force to service innovation, to illustrate the fundamental research of service innovation and service problems for further research to service development.

\section{Theoretical Foundation}

This paper analyses innovation existing in Shanghai Metro System and divides the levels of service innovations following the main contents of MFCSI as follows:

First-level service innovation (primary level): Improving an original service by upgrading in whatever novelty degree which customers unsatisfied to accept it, but it should be recognized by related managers or leaders.

Second-level service innovation (junior level): Introducing a new service which has been offered by other service provider, mainly human power and sometimes needing some kinds of easy getting little goods, but for the enterprise or firm concerned, this kind of service is offered first time. 
Third-level service innovation (Intermediate level): Developing a new service according to the needs of customers, such relatively new service is provided with the human power by the staff alone. There is no need for special equipment or other resources for such new services.

Fourth-level service innovation (the higher level): Developing a new service according to the needs of customers, such new service is provided with the support of special equipment or facilities (hardware or software), which are existing or and easy to get in the market.

Fifth-level service innovation (the highest level): Developing a new service according to the needs of customers, such new service is largely dependent on some service equipment or facilities (hardware or software), which are not existing or difficult to get in the market, and need the service providers to offer them specifically. The service providers can choose to design and produce them by themselves or designate professional agent to develop them. (Mu Yu \& Xu Ming, 2011).

\section{Literature Reviews}

The first Metro line of the world was started 150 years ago in London .It was constructed in October 1863 and finished in 1884. It is a new generation of transportation of the world. It also brought the new page of development to London, whether in public mass transportation or affected to the image of country in being the leader of technology and high development country also influenced metropolitan railroad around the world. Many nations model their subway systems after The London underground. In China the first metro line was opened in 1969 in the capital city-Beijing, under the assistance of Soviet Union. The second line was operated in Tianjin in 1970 and opened in 1984 and followed by Hong Kong in 1979, Shanghai in 1990, Guangzhou in 1993 and some other lines. Up until now, there are subways operated in many large cities in China.

After the first electronic ticket machines were launched as a new innovation by The London Underground in 1918, many nations started to change their operation to be more technological and innovative. In China: Beijing subway had operated the cheapest ticket fee in China. Primarily, the ticket was sold via ticket officers in small box ticket booths, the ticket was just a small piece of paper. However after June 2008, it was changed to electronic card, and the electronic ticket machine service had been operated. Including the transfer system within the stations, Beijing subway stations were operated by the stair case in some stations that caused the passengers some inconvenience who need transiting between the lines. The Chinese government has considered this problem, so the new lines in Beijing has been constructed with elevators and electronic stairs in every station, including the electronic ticket machines. Shanghai metro was under the same situation. In the first two lines, in subway stations, there were normal stairways, but after long experience and studies from other countries, the new lines of shanghai subway stations that were equipped with electronic stairs, elevators, electronic ticket machine and other additional innovative services. In Guangzhou, all of the subway stations were operated electronic stairs and elevators, too.

There are several service innovations in public transit system, especially in metro service, but there are really limited researches in this field. As the evidence, the research done by CoMET (Community of Metros) on "CoMET and Nova Newsletter"(Anderson, 2006), but the most detailed research was the investigation done by Cooperative Mobility Program Center for Technology Policy and Industrial Development Massachusetts Institute of Technology. They investigated the innovation in transit service and operations in several cases from many countries such as USA, Austria, Italy, Germany, Singapore, UK, France etc. It introduced many cases such as using GPS and IT to manage, support and provide passenger information systems, service deregulations etc. (Cooperative Mobility Program Center for Technology, 2013).

\section{Methodology}

The purpose of this research was to investigate service innovation cases along with customer's satisfactions and opinions of passengers to the metro services system, and also be the foundation to further study in Metro Passengers Behavior Guiding System of Shanghai Metro's stations. The methodology of research was conducted as follows:

\subsection{Data Collections}

\subsubsection{Web Investigation and Analysis}

Collected The secondary data via websites, especially the Shanghai metro company's, investigated the shanghai subway's development and specify various classes of service innovations that have been illustrated within last five years in Shanghai Metro System by using Model of MFCSI Model. 


\subsubsection{Field Observation and Survey}

Explore the service problems existed in Shanghai Metro Company, via field observation and survey the five stations that located in downtown and office building zones, which are 1) Zhongshan Park 2) People Square 3) Yan'an West 4) Shijidadao 5) Shanghai Railway Station were chosen to do a deep investigation; The passenger's riding behavior, satisfaction, opinion and recommendation to provide service will be collected via interview and observation.

\subsubsection{Management Interview}

Randomly select 36 staffs to perform the In-depth interview. Investigate service problem and the social activities existed in shanghai subway, the driven forces and support to service innovation development within company.

\section{Results}

\subsection{Basic Survey to Service Innovation Existed in Shanghai Subway Company}

According to "The Model of Five Level Classifications of Service Innovation in Enterprises (MFCSI)" Concept, scholars collected the information mainly via Shanghai Subway Company's website, some via other related online resources, and then defined the service innovation existed in Shanghai Subway Company as follows:

\subsubsection{Primary Level}

Improving an original service by upgrading it in whatever novelty degree, but it should be recognized by related managers or leaders. The cases were defined as follows:

1). Special service for senior passengers (Yuan Sixiang, 2013)

a) Priority service policy; The Company actuates staffs to emphasize service mind and offer priority service to the elders. For instance; provide the special seat, senior special pass lanes, ticket buying lanes etc.

b) Senior Seat service; Owing to "Senior pass card" for elder passengers are unavailable during rush hours; 7:00-9:00 and 17:00-19:00, many passengers had to wait around the station, hence the company was arrange more seats within station to supported them.

2). Extraordinary attention for special occasionally policy

Shanghai Metro Company usually promulgates intensive service for special occasion to facilitate the unprecedented number of passengers for instant during Chinese Festival, Labour Holiday etc.

a) Qingming Festival (Wang Beijun, 2011 \& Chen Kuang, 2012); provided the additional services as; the shuttle bus service to the cemeteries near the stations, The information card to introduce nearby cemeteries, shuttle bus information (time schedules, parking points etc.), special lane for seniors, arranged the waiting areas and the information banners for support a large number of passengers during the festival.

b) Spring Festival (Chinese New Year).

1) Double bullet train \& Waiting Room service (Du Yuan, 2013); provided the waiting area for supporting a large amount of passengers during the festival.

2) Introduction card service (Lin Chen, 2013): provided the Introduction card of train's ticket offices around the stations, selling date and so on to facilitate the passengers who travel during the festival.

3). Twice warning announcements service

Increased safety riding by providing the twice departure warning announcements.

4). Weather forecast information service (Huang Feifei, 2012)

During the season changing in march, the weather was fluctuate, thus the company provided the weather forecast information service, increased more 3 days forecast information, to facilitate passengers in office building zones around Dashijie area.

5). Sanitary toilets (The Forth Operating Company, Shanghai Metro, 2012)

a) At Children medical center station of Line No.6, they increased cleaning staffs during rush hours to keep toilets hygiene all the time (Zheng Manyan, 2013).

b) The toilets in line No.6 and 8 also launched 5 initiatives to improve the sanitary conditions, for instance; freshener fragrance adjusted the exhaust fan, automatic sensor faucets and increased the cleaning inspections.

During summer, there was lot of passengers washing in toilets which caused wet floor, so the company 
provides the non-slip pads in toilets to increase passenger's safety.

6). Line officer service

Provided the volunteers and officers to suggest and supervise the passengers to follow the station's guiding regulations; queuing up, orderly transfer between train and platform to achieve the ride safely and tidily during rush hours.

7). Improve the passenger behavior guiding system

a) The sticker signs that guide the transference between line No. $3 \& 4$ from characteristic system was changed to color system.

b) The guiding banners was also changed to LED banners to prevent fire.

c) Added the caution signs at two sided of escalators to guiding the safety ride (Yuan Sixiang, 2012a)

d) LED caution line at the platform (Yuan Sixiang, 2012b).

\subsubsection{Junior Level}

Introducing new service which has been offered by other service provider, mainly human power and sometimes needing some kinds of easy getting little goods, but for the enterprise or firm concerned, this kind of service is offered first time. The cases were defined as follows:

\section{1). Ticket Services}

a) 1 Day \& 3 Days Passes card: Shanghai Metro Company provided special passes cards for unlimited ride within 1 day at $18 \mathrm{CNY}$ and 3 days at $45 \mathrm{CNY}$. This kind of service also existed in many cities such as Tianjin, Hangzhou, Guangzhou, Shenzhen, Hong Kong "The Octopus Card", Taiwan as "The Gondola / Taipei Pass / MRT-one-Day Pass card". They also existed in many countries around the world such as Bangkok-Thailand, Japan-Tokyo as "Tokyo Free Kippu Card, Korea as "M-Pass", Tokyo-Japan as "Tokyo Metro Open Ticket / Toei One-Day Economy Pass / Tokunai Pass card", Singapore as "Tourist pass / EZ-link card", New York as "Unlimited ride metro card", London as "London travel card" and so on.

b) One smart card to connect to the other public transportation services: The use of smart cards as a transit fare is expanding rapidly overseas. The benefits of smart cards are obvious. They speed up boarding, eliminate the need for cash transactions and cash collections, reduce fraud, protection against theft available (when reported lost or stolen, the card can be electronically "blacklisted" to prevent further use), provide capability to have a more complex regional fare structure, and enable transportation operators to have more accurate ridership data. It can also combine the payment information to the other transportation services. Although in capital city, Beijing, is still lacking this kind of smart card in their public transportation system, but in Shanghai Metro system does existed. The smartcard has been combined with the other public transportation service's payment such as bus, boat and taxi .It is very convenient for the passengers. This kind of service is also existed in many cities around the world, for instance; Singapore, Korea, USA, London etc.

\section{2). Wall-Supermarket Service}

According to the increasing amount of smart phone user in shanghai, including the changing of online shopping behavior. People have the confidence and familiarity in shopping online, so Shanghai metro company had provide Wall-supermarket service which is the huge product catalogs on the wall; passenger could use smart phone (IOS and android) scan QR code in the catalog to shop and then pay via Zhifubao or internet banking system. This kind of service exists in Beijing bus station and Korea subway station as well

\section{3). Kiosk Self-Searching Information Service}

Self-searching information services machines. At first, the machines were installed in the main 4 stations; Zhongshan Park, People square, Lujiazui and Xujiahui. After the successful of trail, they were installed in many stations in Line No.2 and 10 which are the main lines to downtown, Airport, Train stations, and important travel spots in Shanghai. It facilitates foreigners and the outsiders to get the introductory information of tourist attractions, transportation, public bus's by themselves. This kind of service had successfully operated in many countries such as Taiwan, Japan and Singapore as well.

\subsubsection{Intermediate Level}

Developing a new service according to the needs of customers, such related new service is provided with the human power solely by the staff. There is no need for special equipment or other resources for such new services. The cases were defined as follows: 
1). 24 Hrs. English Language Information service (Anonymous, 2010)

During "World Expo 2010" at line No. 6 and No. 8 the English information service and 70 volunteers in blue shirts was provided to support and assist the foreigners. They started working from 9:00-21:00. It offered convenience to the foreigners who visited Shanghai during that period

\section{2). Rental Services}

a) Umbrella rental service (Chu Shuiyu, 2013); During The Olympic Games 2008's period, Shanghai Metro Company provided a special service called "Love umbrella Project". It was available on Line No.1, 2, 3, 4, 8,9 in rainy day. Passengers could borrow the umbrella and return it at the destination station at no charge.

b) Book rental service; It is an activity in "Green-reading month Project" called "Ride up borrow, Ride down return". It was held on line No.2. Project was supported by Aizhi Book Stores that located in every subway station. Passengers can borrow one book from Jing'an station by pay $1 \mathrm{CNY}$ fee for reading among the ride, then return to the Aizhi book store at their destination.

c) Bag rental service; At Line No.4, The company provided bag rental service with free of charge, passenger could borrow the bag and return to any customer service point in any station of Line No.4.

$3)$. Free of recharge available within 30 minutes for line transferring

It will be free for passengers to recharge the smart card after they left the station and check-in again to transfer from Line No.1 at Shanxi South station to Line No.10 or from Shanghai railway station to Line No.3 and 4 within 30 minutes, because the stations haven't been connected to each other. Transferring passengers have to walk out of the station to transfer in the new station.

4). Ashtray service (Anonymous, 2013b)

According to the large amount of smokers who travel during the rush hours, Shanghai metro had provided the ashtrays to increase the safety within the stations.

5). Triple service set (Yan Peishun, 2012)

Line No.8 had provided the "Triple service set", which included mobile ticket scanner and route map set, Coin exchange service set and First aids set, to convenient the passengers during rush hours.

6). Passenger behavior guiding system

The company provided several types of guiding systems. Classified to 3 categories:

a) Digital Media as TV Program or VDO Clips to introduce rules of riding, appropriate behavior of riding, how to behave in an emergency situation, introduction of using devices in the convoy.

b) Media Banners such as smear campaigns billboards, rule of riding introduction's billboards, guide line stickers that lead to the transfer paths, the safety warning sticker banners at the platform's gates, etc.

c) The Staffs; arrange the staffs at the platforms to supervise and giving the riding's information during rush hours.

\section{7). Music Station Service}

Available in Line No. 8. They provided the music bands at one corner in the station to play classical and temporary music.

\subsubsection{The Higher Level}

Developing a new service according to the needs of customers, such new service is provided with the support of special equipment or facilities (hardware or software), which are existing or and easy to get in the market. The cases were defined as follows:

1). Kids playground service (He Zhijun, 2012)

A small kid playground in Shanghai Children's Medical Station of Line No.6. It is a special support for children and parents who came to Medical center, to spend their time to waiting, after registration at the hospital. There are many balls, toys and playing area for kids and also the waiting area for the parents.

2). Braille map service (Anonymous, 2012a)

At Shui Cheng Road station in line No.10, the company provided the Braille map and Braille route information to convenient the students in Shanghai School for the Blind that located near the station.

3). Safety light line \& announcement service 
Installed the caution sound at the escalators to increase the safety and convenience for blind passengers.

4). Train status's light

Line No.10 had provided the LED light in the convoy to show the current station.

5). TV on train (Xu Huili, 2012)

Establish their own TV station (SMTV) and produce the TV programs to show on TV in the train in Chinese and English. The Programs included the rule of riding, Using manual, Security introduction, News, Shanghai travel spots and etc.

\section{6). Mobile Application}

Currently, there are 30-50 mobile applications that provide information about shanghai metro lines which developed by various developers. They are available for both on IOS and Android system, both in English and Chinese. The official one is shown by Shanghai subway's logo. It was developed by Shanghai Metro Company and firstly launched in 2011 as version 1.0. Until 2013-09-30, it was upgraded to version 3.0 with additional useful information such as station floor plan, exit map, toilet map, time schedules, the estimate arrival time calculation, reading box, convenient store, food and beverage and shopping place nearby the station. It facilitates the passengers to get the travel information at any time.

\section{7). Top Up Service}

Shanghai Metro Company provides the Top Up Service to the passengers in many channels apart from counter services as follows;

a) Internet top up service;

b) Convenient stores top up service; passenger could top up transportation card at Ke'Di or Haode, the convenient stores that located at every corner around shanghai city.

8). Train Schedule information

The LED billboards had been provided at every platform to announce train schedule; next train's estimated arrival time and next train's situations.

\subsubsection{The Highest Level}

Developing a new service according to the needs of customers, such new service is largely dependent on some service equipment or facilities (hardware or software), which are not existing or difficult to get in the market, and need the service providers to offer them specifically. The service providers can choose to design and produce them on own or designate professional agent to develop them. The cases were defined as follows:

\section{1). Automatic ticket machine service}

The Automatic ticket machines had been provided in every station.

2). Automatic top up machine service

Company provided several machines in every station which could top up by cash, ATM card or credit card by union pay.

Service innovations in Shanghai Subway have been developed during these several years. Since 2000, there existed the evidence; they launched the transportation smart card service. This was the $2^{\text {nd }}$ level of service innovation that occurred first time in Shanghai metro system. It was only evidence in year 2000. In 2007 and 2008 , there illustrated just one project per year and increased in 2009. They purposed 4 new service projects that included the service innovation in the $2^{\text {nd }} 3^{\text {rd }}$ and $4^{\text {th }}$ level. In 2011, they were lunched 13 service innovation and service development projects. Also more 10 projects in 2012 as well. In 2013 until October had launched out 7 projects already. Almost every month, they would launch a new projects or programs to support the services. This does not included many social activities that the Company launched some project to support the services. They launched 12 projects of social activities during 2012 and 25 projects in 2013 (until October). These could be the evidences of the increasing of service innovation, and could be called the new era of service development or service innovation in Shanghai Subway System. 


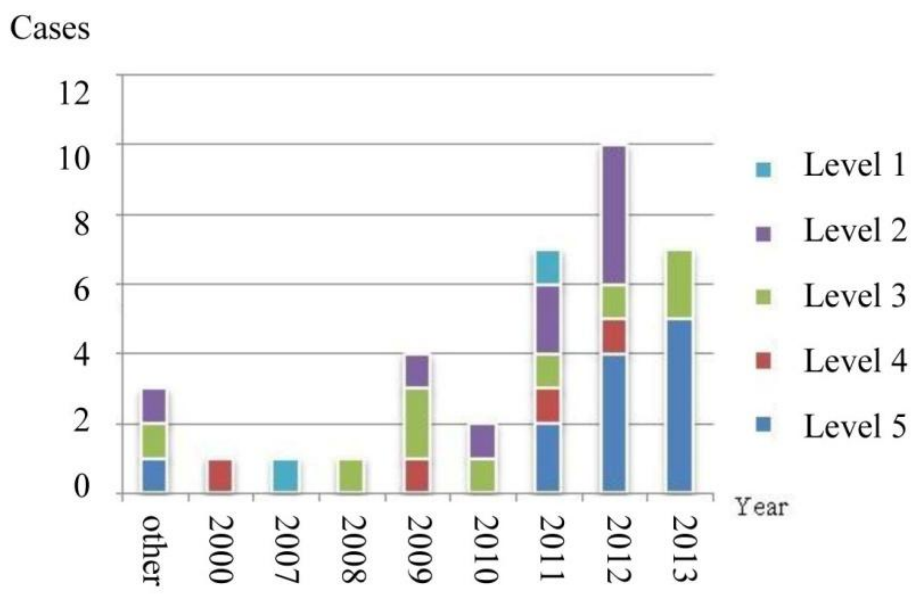

Figure 1. Service innovation in Shanghai metro system based on MFCSI model, analysis classified by year

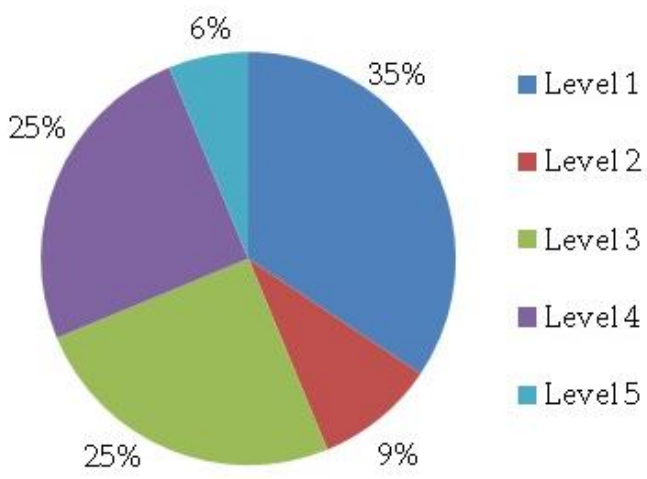

Figure 2. Sservice innovation cases during 2000-2007 based on MFSCI model, analysis classified by level

However, current problem in service sector is not obvious, the results illustrated that most problems came from the management side. For service sectors, the service innovation that existed in Shanghai Subway mostly are Primary Level $\left(1^{\text {st }}\right)$, Intermediate Level $\left(3^{\text {rd }}\right)$ and Higher Level $\left(4^{\text {th }}\right)$ but, still lacks of the Highest Level $\left(5^{\text {th }}\right)$ of service innovation, which are developing a new services according to the needs of customers, and service have to largely dependent on some service equipment or facilities (hardware or software), which are not existing or quite difficult to get in the market, and need the service providers to offer them specifically.

\subsection{Passenger Satisfactions Analysis}

This part of research was done via interviewed one hundred passengers in five stations, which are People Square, Yan'an West, Zhongshan Park, Shijidadao and Shanghai Railway Station. The questions purposed to examine the satisfaction, opinion and recommendation in overview. The results illustrated that passengers was quite satisfied to the service management and quality. Forty-four percents of samples mentioned that the most satisfied factor is the routes covered several main areas around shanghai, make the convenience transportation access. Sixteen percents mentioned to the good service quality. Fifteen percents of samples mentioned to punctuality of the train and frequency of trains are appropriate during the rush hours. Furthermore, the samples complimented the good environment within the stations, the passenger guiding systems and staffs service-minded. 


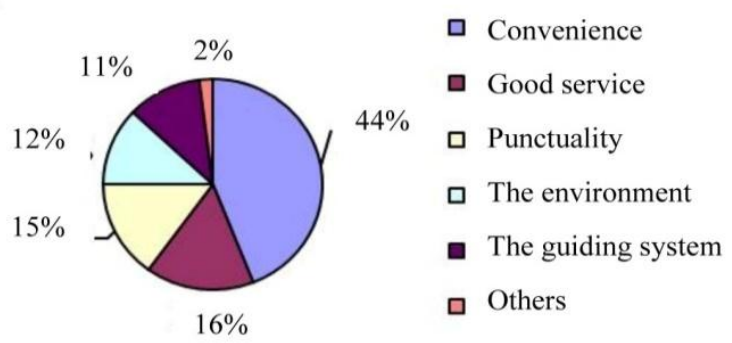

Figure 3. Passenger satisfaction results

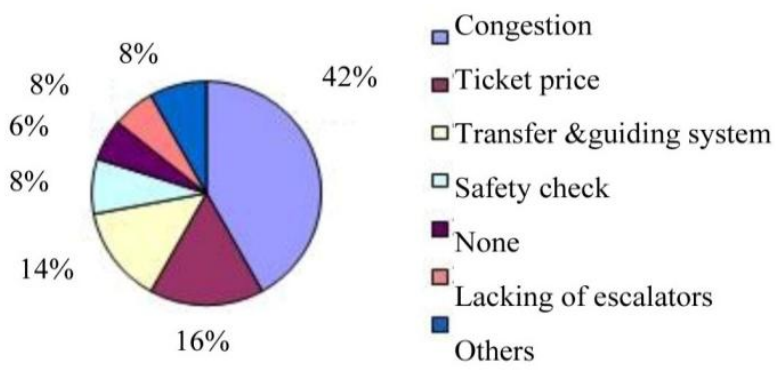

Figure 4. Passenger unsatisfied results

However, Most of the samples, Forty-two percents, mentioned that the most unsatisfied is the congestion within the train included the crowd and disorderly transfer passengers between the lines. Sixteen percents mentioned to the ticket was quite expensive. Fourteen percents of samples concerned about the passenger guiding and Transfer systems such as exit information and transfer information banner which are still deficiency. Some station is still lacking the safety gates between train and platform. The baggers, toilets and lacking of seat and escalators also were mentioned as the problems from the passenger point of views. Actually, lacking of escalators could be considered as a part of transfer and guiding system, hence, The unsatisfied result in transfer and guiding was reaching twenty percents or one-five of all samples. It could imply, there still existed the problem and inefficiency in services.

\subsection{Staffs in-Depth Interview Analysis}

This part of research was done via interviewed thirty-six managerial and operational staffs in the same five stations. One manager and four to six on duty officers per station which are represent 50 percents of on duty staffs at the platform zones in each day. The purpose of the questions is to examine the problems existed in service operations. The results illustrated that most serious problems are crowed and disorderly transfer passengers between the lines are the most. The congestion of the passengers who tried to ride at the platform is also another problem. More than one-third of staffs have confronted with passengers who disobey the rules. Eleven percents have faced with communication problems. Another eleven percents mentioned to their problems in reaction in emergency situations. The other seventeen percents mentioned to the beggars and drunks. Anyway, from the managerial overviews, one of the most serious disobeys' problem is ticket evasion.

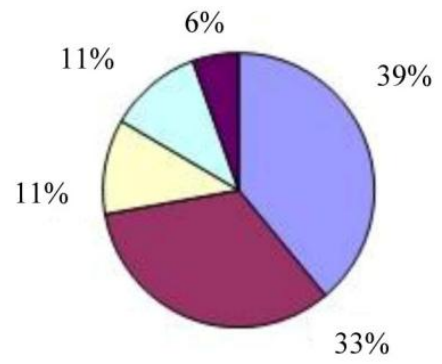
․ Passenger disobey the rules
- Communication with passenger
․ Make quick reaction to the emergencies
․ The beggars
- The drunks

Figure 5. The problems existed in service operations from managerial and operational staffs' point of view 
From the results, they illustrated that the customer satisfaction to both services and staffs are quite high, because Shanghai Subway Company had continuously improved and innovated the new services, especially in the first and fourth level. However, it still lacks of the fifth level. It might be caused from the cost of development which is extremely high and the procedure is quite complicated. Shanghai Subway Company is a state enterprise. It is the monopoly market without competitors, so there is no need to set the fifth level of service innovation as a strategy in the first step to keep market share from other competitors. It possibly may be caused by obstacle from investment. Hence in the future, in the first step, company should set the strategy to increase more service innovation in the third level. The development should be based on the needs of customers and provided by the human power by the staff alone. There is no need for special equipment or other resources, along with R\&D department and personnel reward system to motivate staffs to create newer and more proficient services. In the future, the development of new service may be focused on the fifth level to create a unique service and facilitate the increasing of customer in the near future.

\section{Findings}

Shanghai Metro's official website is not only a masterpiece of the service communication, but it is also a positive force of service innovation encouragement. The website has been released 300 sets of information to the public for one and a half year. There are about 32 items which were directly associated with service innovations according to the model of MFCSI. These have not included several social activities that indirectly supported to the service. These could be implied as a part of service innovation as well. Hence, the scholars would like to applaud their great efforts for the public.

According to the model of MFCSI. Therefore, the service innovations that occurred in Shanghai Metro System in from the $1^{\text {st }}$ to the $5^{\text {th }}$ level amounts as the following order; $11,3,8,8$, 2 cases. Among them, the $1^{\text {st }}$ Level is the most, the $4^{\text {th }}$ Level and the $5^{\text {th }}$ Level are about one-third of total.

The MFCSI - The Model of Five Level Classifications of Service Innovation in Enterprises - is a useful tool to analyze the contribution of innovation within service enterprises and theirs activeness in service innovation, especially for large scale service enterprises or firms. Meanwhile, present concept of MFCSI has showed the several points as defects which should be further improved concerning its development.

\section{Discussions \& Further Researches}

\subsection{The Definition Improvement of MFCSI}

Concerning the definition of first level of the model, customer acceptance or satisfactory should be considered first, otherwise, such improvement or newness is useless.

Concerning second level of the model, present definition only mentions that sometimes this level of service innovation needs some kinds of easy getting little goods, this time we need to expand the "little goods" into together with some equipments or facilities, and, of course, those are easily to get. The second level of service innovation usually needs few research and development, which needs to be added into the definition.

The research finds that, there are lots service innovations combined with social activities and service for corporate social responsibility purposes, such as the services provided by volunteers, special gifts on cultural festival, distributed some free vitamins during rainy season to prevent colds and so on. How those efforts related to social responsibility could be involved with the definition of MFCSI, which are worth for further development. According to our opinion, those activities with social responsibilities should be included into the categories of new service or service innovation.

\subsection{The Driving Force of Service Innovations}

The distribution of service innovations in Shanghai Metro System indicated that different lines have quite different features related to service innovation diffusion, that is to say, one innovative service activity in one line may not be applicable in another line, even the situation is similarity, also under the same rules of management. Therefore, in this paper, scholars would like to discuss a little about the driving force of those service innovations. We also found that, high levels of service innovation are really few in Shanghai Metro System. According to the difficulty degree to the different levels of service innovations, higher levels of service innovations require more efforts from high level of management and also more resources(financial, human and management) are needed, so where are the driving force coming from to push forward such innovation development comes from? According to our investigation, we would like to specify two kinds of forces. The first one is external needs from customer and government guiding policy and the second one is internal needs, which is up to down supervision power in the system. But what is the real mechanism for such systematical situation, and definitely we need further research about it. 


\subsection{The Attention Should Also Be Related to Lower Levels of Innovations}

The hints from our investigation teaches us that lower levels of service innovations are widely needed for getting more satisfactory from customers. For example, the guiding system in Shanghai Metro system is regarded as acceptable, but compared with higher level of quality management standard, it needs further improvement. We have seen that different lines have different guiding sign systems in platform, which formalization innovation could be used to upgrade the whole system. Such improvements related to MFCSI are regarded as lower level of service innovations, whereas those efforts are definitely needed for the system improvement. Nowadays in Shanghai, the huge crowds of passengers always causes severe troubles to the management, the better guiding system will be the economical solution for the issues.

\section{References}

Anderson, R. (2006). Improving the management and delivery of mass public transportation in cities. Conference "Nova Symposium", Nova and CoMET, Buenos Aires, April 2006.

Anonymous. (2010a). Shanghai Subway launched 24 Hrs. English service. Changchun Newspaper. Retrieved from http://news.china.com.cn/rollnews/2010-05/01/content_1905011.htm

Anonymous. (2012b). Line No.10 provided Braille map service. Party office Group. Retrieved from http://www.shmetro.com/node49/201205/con111678.htm

Anonymous. (2012c). The passengers of Shanghai Metro reach 7,000,000 in working day. Retrieved from http://roll.sohu.com/20120330/n339432359.shtml

Anonymous. (2013a). Shanghai Statistics Bureau, National Statistic office, Shanghai Survey Team. 2012 Shanghai Municipal Economic and Social Development Statistics Bulletin. Retrieved from http://www.stats-sh.gov.cn/sjfb/201302/253153.html

Anonymous. (2013b). Provided the ashtrays within 13stations to increase the safety in the stations. The First Operating Company, Shanghai Metro, Shanghai Shentong Subway Group Cooperation Limited. Retrieved from http://www.shmetro.com/node78/node80/201307/con113220.htm

Anonymous. (n.d). Cooperative Mobility Program Center for Technology, Policy and Industrial Development Massachusetts Institute of Technology. International Mobility observatory: Innovation Fact Sheet.

Beijun, W. (2011). Map service during Qingming Festival. The Second Operating Company, Shanghai Metro, Shanghai Shentong Subway Group Cooperation Limited. Retrieved from http://www.shmetro.com/node65/node66/201104/con107609.htm

Chen, L. (2013). Service card during Spring Festival. The Forth Operating Company, Shanghai Metro, Shanghai Shentong Subway Group Cooperation Limited. Retrieved from http://www.shmetro.com/node65/node66/201302/con112723.htm

Feifei, H. (2012). 3 Days Weather forecast service on Line No.8. The Forth Operating Company, Shanghai Metro, Shanghai Shentong Subway Group Cooperation Limited. Retrieved from http://www.shmetro.com/node65/node66/201203/con111308.htm

Huili, C. (2012). Shanghai Metro Center, "SMG Campaign". Shanghai Shentong Subway Group Cooperation Limited. Retrieved from http://www.shmetro.com/node49/201308/con113334.htm

Kuang, C. (2012). Three Core services. The Second Operating Company, Shanghai Metro, Shanghai Shentong Subway Group Cooperation Limited. from http://www.shmetro.com/node78/node80/201204/con111362.htm

Manyan, A. (2013). The Forth Operating Company, Shanghai Metro, "Contribute Toliets-decorative planning on line No.6". Shanghai Shentong Subway Group Cooperation Limited. Retrieved from http://www.shmetro.com/node49/201305/con113001.htm

Peishun, Y. (2012). Triple Set service available on Line No.8. The Forth Operating Company, Shanghai Metro, Shanghai Shentong Subway Group Cooperation Limited. Retrieved from http://www.shmetro.com/node65/node66/201211/con112434.htm

Qiang, W. (2013). The passengers of Shanghai Metro reach 84860000. Xinmin Newspaper, Wenhuimin United Press Group. Retrieved from http://xmwb.news365.com.cn/zh/201303/t20130309_997764.html

Shuiyu, C. (2013). Shanghai Metro provide Aixinsan umbrella rental service. Retrieved from http://www.ditiezu.com/thread-39894-1-1.html 
Sixiang, Y. (2012a). The LED caution signs was added at the Yishanlu Station on Line No.3. The Third Operating Company, Shanghai Metro, Shanghai Shentong Subway Group Cooperation Limited. Retrieved from http://www.shmetro.com/node65/node66/201211/con112460.htm

Sixiang, Y. (2012b). The LED caution signs was added at the gate. The Third Operating Company, Shanghai Metro, Shanghai Shentong Subway Group Cooperation Limited. Retrieved from http://www.shmetro.com/node65/node66/201211/con112429.htm

Sixiang, Y. (2013). Service to elder, side by side. The Third Operating Company, Shanghai Metro, Shanghai Shentong Subway Group Cooperation Limited. Retrieved from http://www.shmetro.com/node65/node66/201306/con113135.htm

The Forth Operating Company, Shanghai Metro. (2012). Triple Set service available on Line No.8. Shanghai Shentong Subway Group Cooperation Limited. Retrieved from http://www.shmetro.com/node65/node66/201208/con112184.htm

Wikipedia. (2013). Shanghai Metro. Retrieved from http://en.wikipedia.org/wiki/Shanghai_Metro

Yu, M., \& Ming, X. (2011). Hints from the Application of the Mode of Five-level Classification of Service Innovation (MFCSI) in Enterprise to Disney's Services. Conference "Theme Park and Urban Tourism" International Symposium", East China Normal University, Shanghai, Nov., 2011.

Yuan, D. (2013). Double bullet train \& Waiting Room service during Spring Festival. The First Operating Company, Shanghai Metro, Shanghai Shentong Subway Group Cooperation Limited. Retrieved from http://www.shmetro.com/node65/node66/201302/con112747.htm

Zhijun, H. (2012). Kids playground service on Line No.6 had good feedback after 1 month operated. The Fourth Operating Company, Shanghai Metro, Shanghai Shentong Subway Group Cooperation Limited. Retrieved from http://www.shmetro.com/node78/node80/201305/con113094.htm

\section{Copyrights}

Copyright for this article is retained by the author(s), with first publication rights granted to the journal.

This is an open-access article distributed under the terms and conditions of the Creative Commons Attribution license (http://creativecommons.org/licenses/by/3.0/). 